\title{
Emotional Stress Evaluation of Patients with Moderate and Severe Sleep Apnea Syndrome
}

\author{
Micheli Aparecida Gomes dos Santos ${ }^{1}$ Tatiana de Cássia Nakano ${ }^{1}$ Felipe Almeida Mendes ${ }^{2}$ \\ Bruno Bernardo Duarte ${ }^{3}$ Silvio Antonio Monteiro Marone ${ }^{3}$
}

${ }^{1}$ Department of Psychology, Pontifícia Universidade Católica, Campinas, São Paulo, Brazil

${ }^{2}$ Department of Otolaryngology, Pontifícia Universidade Católica, Campinas, São Paulo, Brazil

${ }^{3}$ Department of Otorhinolaryngology, Pontifícia Universidade Católica, Campinas, São Paulo, Brazil
Address for correspondence Felipe Almeida Mendes, Department of Otolaryngology, Pontifícia Universidade Católica, Av. John Boyd Dunlop Jardim Ipaussurama, Campinas, São Paulo 13060-904, Brazil (e-mail: felipemendes@hotmail.com).

Int Arch Otorhinolaryngol 2017;21:28-32.

\begin{abstract}
Keywords

- sleep apnea

- obstructive

- stress

- psychological

- evaluation studies
\end{abstract}

\section{Introduction}

Obstructive sleep apnea (OSA) is characterized by recurrent collapse of the pharynx during sleep, resulting in substantial reduction of airflow (apnea or hypopnea) leading to intermittent disorders of blood gases (hypoxemia and hypercapnia) and activation of the sympatic system ${ }^{1}$.

received

February 14, 2016

accepted

June 18, 2016

published online

August 16, 2016
Diagnosis of OSA is made by clinical history and polysomnography, defined by an apnea-hypopnea index (AHI) greater than 15 or AHI greater than 5 with daytime and nighttime symptoms. The severity of the apnea is classified as mild (AHI 5 to 14.9), moderate (AHI 15 to 29.9), and severe (AHI greater than 30$)^{1}$

Copyright @ 2017 by Thieme-Revinter Publicações Ltda, Rio de Janeiro, Brazil
License terms

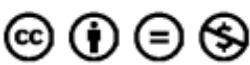


Tuffik et $\mathrm{al}^{2}$ showed in their study that, among 1042 volunteers, $32.8 \%$ presented the criteria for OSA according to the American Academy of Sleep Medicine (discovered by overnight polysomnography). Prevalence estimates are higher among men and increases in both genders with the aging. ${ }^{3}$ OSA was more prevalent in overweight and obese men and women. ${ }^{2-4}$

Symptoms of stress are frequent in patients with OSAS. According to Lipp, ${ }^{5}$ stress is a general wear and tear of the body caused by psycho-physiological changes that occur when the individual is forced to face a situation that arouses a strong, good or bad emotion, which requires changes.

The most common symptoms of emotional stress are: tachycardia, excessive sweating, muscle tension, dry mouth, and feeling of being on alert. ${ }^{4}$ In the course of its development, the differences manifest according to individual genetic predispositions, potentiated by possible impairments developed later in life, such as accidents and diseases. ${ }^{6}$

The scientific literature has shown that the damage caused by sleep fragmentation in people affected by OSA can reflect emotionally, generating not only physical symptoms, such as drowsiness and tiredness, but also psychical symptoms such as stress. ${ }^{7}$ Considering this fact, the aim of this study was to compare stress symptoms in patients with OSA, moderate and severe before and two months after the start of clinical or surgical treatment.

\section{Methods}

The project received approval for execution from the Ethics Committee of the University that houses it. Patients signed an Informed Consent in which they agreed to participate. Subsequently, the data was disclosed for scientific purposes anonymously. Offering medical care or treatment was necessarily conditional to participation in our research.

We conducted the study at an outpatient clinic specialized in sleep medicine, a division of the Otorhinolaryngology Service of a university hospital in the state of São Paulo.

This study is characterized as individualized, prospective, longitudinal, and interventional. There were no control group or blinding of assessors.

All patients received treatment at the Otorhinolaryngology ward and were sent to sleep medicine clinic equipped with polysomnography type I, which always took place in the same laboratory.

We performed the data collection through the use of an identification questionnaire prepared to obtain demographic data of the participants and the Lipp's Inventory of Stress Symptoms for Adults (ISSL). ${ }^{8}$
The ISSL is an instrument that assesses symptoms of stress, the patient́s stress level (alarm, resistance, near-exhaustion, and exhaustion), and the kind of predominant symptoms present (physical or psychological). The instrument consists of 53 items, 34 concerning the physical conditions of psychological and 19, divided into three quadrants. The first frame shows symptoms experienced in the last 24 hours, 12 being physical and three psychological. The second shows symptoms in the last week, 10 physical and psychological 5 . The third frame includes symptoms experienced in the last month, 12 physical and 11 psychological. Evaluation of responses is done through the use of the ASSI guide tables, which transforms the raw data into percentages.

In the first evaluation with the participants before the start of treatment for OSA, we applied the socio-demographic questionnaire and the inventory of stress. At the second meeting, after two months of treatment (medical or surgical), we only applied the inventory.

The initial sample consisted of 23 participants; however, five patients did not adhere to treatment and were excluded from the final sample. Thus, the final sample consisted of 18 patients with a mean age of 51.83 years, minimum 26 years and maximum of 74 years $(\mathrm{SD}=13.46)$. In this group, $72.2 \%(n=13)$ were men. Regarding education, there was a higher frequency of participants with incomplete primary education with $55.6 \%(n=10)$ and, in relation to marital status, $83.3 \%(n=15)$ were married. We determined type of OSA by overnight polysomnography and found that $72.2 \%(n=13)$ of the sample suffered from severe OSA and $27.8 \%(n=5)$ had moderate OSA.

We did not include patients who suffered from mild OSA because they did not fit the inclusion criteria.

\section{Results}

The evaluation of the results obtained in the ISSL allowed the identification of stress levels presented by individuals and we observed that $77.8 \%$ ( $n=14)$ of patients had stress in the first evaluation. In the second evaluation after treatment, the amount fell to $16.7 \%(n=3)$.

To better visualize the data, descriptive statistics from before and after treatment are shown in - Table 1. The average stress symptoms drop significantly from the first to the second evaluation ( $\mathrm{M}=13.78$ and $\mathrm{F}=6.17$, respectively).

The non-parametric Wilcoxon test was used to assess the most common symptoms of stress pre and post treatment. The results showed that patients experienced a statistically significant decrease in mean symptom of post-stress treatment $(\mathrm{z}=-3.53, p<0.000)$.

Table 1 Descriptive statistics for stress pre and post treatment

\begin{tabular}{|l|l|l|l|l|l|l|l|}
\hline \multicolumn{1}{|l|}{ ISSL - Total } & N & Mean & Median & Minimum & Maximum & SD & SS \\
\hline & 18 & 13.78 & 12.50 & 2 & 29 & 7.56 & 1.78 \\
\hline Pre & 18 & 6.17 & 4.0 & 0 & 22 & 5.91 & 1.39 \\
\hline Post &
\end{tabular}

Abbreviations: ISSL, Lipp’s Inventory of Stress Symptoms for Adults; SD, standard deviation; SS, statistical significance. 


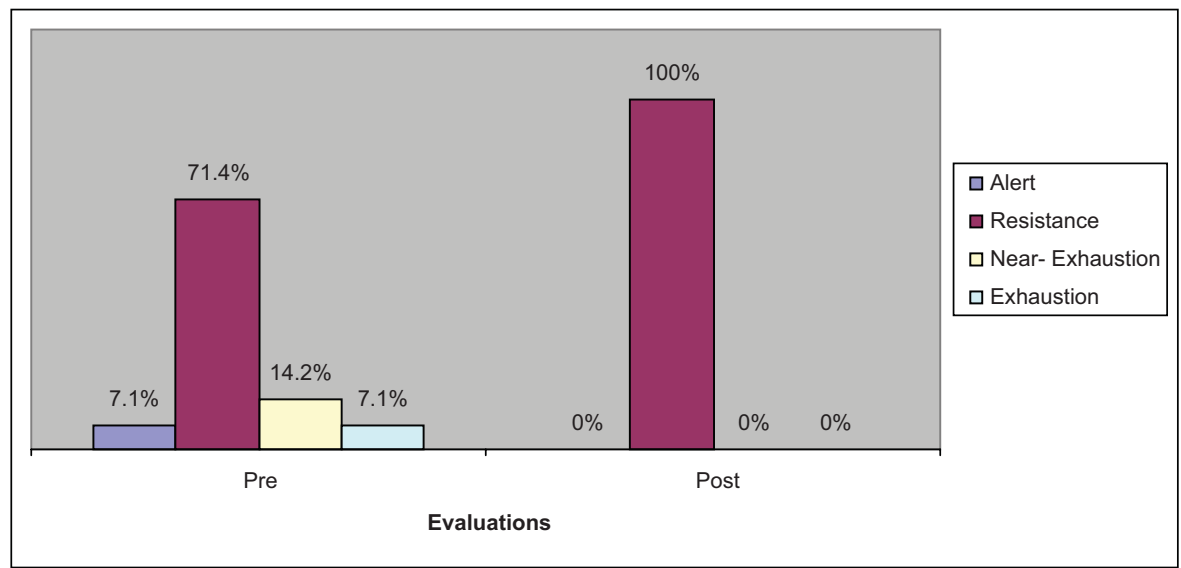

Fig. 1 Percent stage of pre-treatment and post stress.

To further investigate this situation, a second analysis sought to determine which stages of stress prevailed in both evaluations among patients who were stressed, as shown in - Fig. 1.

We noticed important changes in the second evaluation, given the fact that only the resistance phase was present in $100 \%$ of individuals who remained stressed after treatment $(n=3)$.

We performed a more detailed investigation to identify the predominant symptom (physical or psychological) in individuals with stress, whose data are presented in -Fig. 2.

The results from the ISSL showed that the feeling of constant physical wear is the most commonly reported by patients, persisting in the second assessment (in 66.7\% of cases in the first evaluation and 33.3\% in the second evaluation). Memory problems also showed high prevalence, present in $55.6 \%$ of cases before treatment and in $38.9 \%$ of patients after treatment. Approximately $44.4 \%$ of patients had muscle tension and xerostomia in the first evaluation. The most prevalent psychological symptoms claimed by responders in the first evaluation were feelings of anguish and daily anxiety (61.1\%). Moreover, $55.6 \%$ of the responders reported exces- sive emotional sensitivity and $44.4 \%$ reported excessive irritability. In the evaluation performed after two months of treatment, the psychological symptoms that prevailed were anxiety / daily anxiety (38.9\%), constantly thinking or talking about one subject (22.2\%), and loss of sense of humor (22.2\%).

A second analysis compared the stress between the groups with moderate apnea $(n=13)$ and severe apnea group $(n=5)$. The results pointed to a lower average gift symptoms within the group with moderate OSA ( $\mathrm{M}=11.8, \mathrm{SD}=7.59)$ when compared with the severe OSAS group ( $\mathrm{M}=14.54$; $\mathrm{SD}=7.72$ ) in initial assessment, pre-treatment. In the second evaluation after the beginning of treatment, the mean for decreased symptoms in both groups (mean $=4.6$; $\mathrm{SD}=4.33$ for moderate and $M=6.77 ; S D=6.47$ for severe), although the decrease was higher in the severe OSAS group.

We used the non-parametric Mann-Whitney test to enable the differences between two test conditions and different participants. $^{8}$ The results showed no significant inter-group difference (moderately $\mathrm{x}$ severe) in the first evaluation $(U=24.5 ; z=-0.790 ; p=0.43)$, or in the evaluation performed after starting treatment $(U=26.5 ; z=-0.594 ; p=0.55)$.

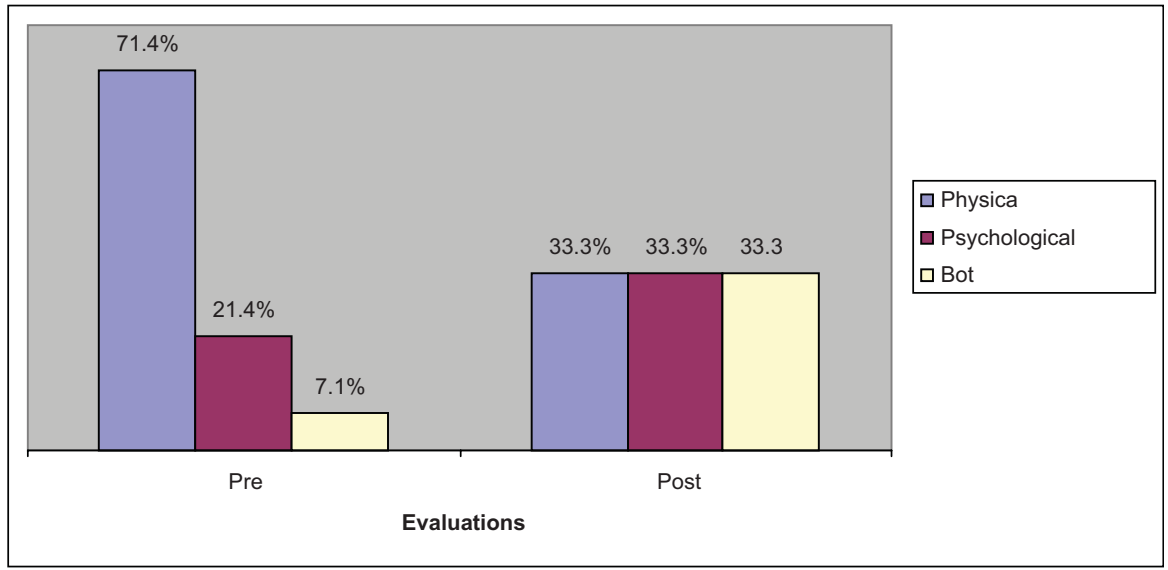

Fig. 2 Prevalence of types of pre and post-treatment symptoms. 
We used a second analysis for intragroup comparison of scores from the same participants (moderate OSA before and after treatment, severe OSA before and after treatment). Results showed that patients with moderate OSA presented a significant decrease in mean symptom of post-stress treatment $(\mathrm{z}=-2.971 ; p<0.003)$; the same happened to patients with severe OSA $(z=-2.023 ; p<0.043)$, demonstrating that the treatment was effective in improving symptoms of stress.

Comparing the symptoms of stress among the women $(n=5)$ with those among the men $(n=13)$, there was a slight decrease in the frequency of stress symptoms in women $(\mathrm{M}=15.4, \mathrm{SD}=8.26$ in the first evaluation and $\mathrm{M}=9.8$, $\mathrm{SD}=8.7$ in the second evaluation) and a relatively greater reduction among the men $(\mathrm{M}=13.1, \mathrm{SD}=7.53$ in the pretreatment and $M=4.77, S D=4.08$ in the post-treatment). By analyzing the differences between the genders in each of the assessments, the results of the Mann-Whitney test at the first assessment $(U=28.5 ; \mathrm{z}=-, 395 ; p=0.693)$ as well as the second $(U=22.0 ; z=-1.039 ; p=0.299$ ) suggest that there is no significant intergroup differences in the two periods. On the other hand, the intra-group analysis showed that women showed no significant improvement in symptoms of stress after treatment $(\mathrm{z}=-1.633 ; p=0.102)$. The men, on the other hand, showed a steep decrease in symptoms $(z=-3.184 ; p=0.001)$.

Finally, another exploratory analysis was to compare patients due to the treatment (CPAP or Lateral Pharyngoplasty). The results showed a significant reduction in anxiety symptoms in the group that underwent treatment with CPAP $(\mathrm{M}=14, \mathrm{SD}=7.57$ before treatment and $\mathrm{M}=6.8, \mathrm{SD}=6.23$ after starting treatment). In the surgical group, the decrease was not as important ( $M=12.67, S D=9.07$ before treatment and $M=3.0, S D=2.64$ after start of treatment).

Given the apparent mean differences, we applied the Wilcoxon non-parametric test. We compared results from patients who received treatment with CPAP in terms of the existence of significant differences in anxiety symptoms from the first to the second evaluation $(z=-3.21 ; p=0.001)$, which did not occur in the group that underwent surgery $(\mathrm{z}=-1.60 ; p=0.109)$.

\section{Discussion}

In terms of psychological evaluation, this study found a significant decrease in stress symptoms in patients after treatment with CPAP, a result similar to the study conducted by Grunstein et $\mathrm{al}^{9}$ based on the hypothesis that the withdrawal of CPAP in patients suffering from severe OSA, would produce a measurable stress response.

Important to note that the stress measurements between the study results presented by Grunstein et $\mathrm{al}^{9}$ and the present study are different mainly in resources used for the diagnosis of stress. Therefore, caution is recommended before any comparison may be performed to affirm the effect of CPAP treatment in patients with OSAS.

The correlation between cortisol and sleep is verified by Spiegel, Leproult, and Van Cauter. ${ }^{10}$ Their study showed sleep restriction (4 hours / day for 6 nights) increased cortisol levels in normal individuals. This finding confirms what has already been pointed out by Spath-Schwalbe, Gofferje, Jern, Born, and Fehm, ${ }^{11}$ who suggest that nocturnal awakenings in OSA are associated with alterations in the hypothalamic-pituitary-adrenal axis (HPA) and claim that intermittent hypoxia, fragmentation, and sleep deprivation causes cortisol release. Therefore, it expected a high level of stress in patients with OSA. ${ }^{11-13}$

We found that most of the sample was in the resistance phase in both evaluations. This phase, an intermediate one in the stress process, is characterized by physical and mental tiredness, memory difficulties, and increased vulnerability to diseases that occur due to poor functioning of the immune system. Productivity can also suffer as a result of the appearance of symptoms. If the body cannot reverse the process, the person enters the stage of exhaustion. ${ }^{14}$

Among the most prevalent physical symptoms during the first evaluation is memory loss. This symptom persisted as the most common physical symptom in post-treatment evaluation. People with daytime sleepiness can present problems in the transfer of short-term memory to long-term, compromising thus their daily activities. 2,3,15

Regarding the psychological symptoms in addition to daily distress or anxiety, irritability and excessive emotional sensitivity were the most frequent in pretreatment. In the second evaluation, distress or daily anxiety remained the most prevalent complaints, followed by thinking or talking constantly in one subject and loss of sense of humor. However, it is important to consider the presence of daytime sleepiness and adaptation requirements to treatment.

When comparing the groups of moderate and severe apnea, the results point to the existence of statistically significant differences related to the stress levels after treatment. In this way, it was possible to verify that the treatment was effective in improving symptoms for both levels of the disease (moderate and severe). Franco, ${ }^{16}$ whose general objective was to evaluate the correlation between the severity of OSA, oxidative stress markers, and the presence of depressive and anxiety symptoms, developed research with similar results. The conclusion was that the greater the severity of OSA, the greater the fragmentation of sleep, increasing the incidence of daytime symptoms, particularly somnolence, depressive and anxiety symptoms. Unlike this study, both in the first assessment and in the second there were no significant differences in the level of stress among the moderate and severe groups.

In this study, when comparing the prevalence of stress among genders, there was no statistically significant differences between groups in the incidence of stress symptoms, either in the assessment performed pre-treatment or post-treatment. However, it is noteworthy that, in the second evaluation, all patients who were stressed were female. In their survey on gender, education, and stress, Calais, Andrade, and Lipp ${ }^{17}$ found that women were more vulnerable to stress than men in all age groups. A similar result was found by Calais. ${ }^{18}$

Regarding the treatment used, we found that patients showed a significant reduction in symptoms after treatment with CPAP. ${ }^{19,20}$ However, patients in this study who have undergone surgical treatment (Lateral Pharyngoplasty) did 
not show a significant improvement in symptoms of stress, which does not correspond to some data in the literature. In $\mathrm{Li}$ et al, $^{21}$ for example, the authors concluded that surgery can significantly improve psychological symptoms in patients with OSAS, although the effect of surgery was mild but clinically relevant. It is worth noting, however, that, due to the short time interval between evaluations, the results may have been influenced by other factors. It is worth mentioning, for instance, the need for further adjustment on the part of patients resulting from the use of CPAP as compared to disturbances from surgery, such as wound healing and side effects of medication.

Cahali, Formigoni, Gebrim, and Miziara ${ }^{22}$ stated that the healing process occurs in 6 to 9 months. Moreover, in the first days after surgery, there is edema of the pharyngeal region, which can narrow the upper airways and worsen OSA framework in this period. The authors say that the results of Lateral Pharyngoplasty reach their peak after a period of three to six months of the procedure, including better clinical and polysomnographic results than uvulopalatopharyngoplasty. ${ }^{22,23} \mathrm{We}$ would recommend carrying out a new assessment 6 months after surgery to verify that these data remain the same.

\section{Conclusion}

The quest for understanding what happens emotionally in patients suffering from OSA is necessary. It is important to point out that this study was conducted with a small sample and, therefore, the considerations presented here should be considered cautiously, avoiding early spreads. We suggest pursuing further studies with a larger sample to obtain data from. This also raises the hypothesis that receiving a diagnosis, as well as the possibility of receiving treatment, may have influenced stress reduction in patients, by which factors other than the treatment itself may have contributed to the reduction in symptoms. It is important that future studies shed light onto other variables that deserve to be better investigated in future studies, such as adaptation to treatment, use of an instrument to evaluate the quality of sleep, or offering an intervention program aimed at stress management and a better quality of life for such patients.

Furthermore, this study presented limitations regarding the absence of control variables, such as obesity and use of medications that could interfere with the results, which we consider intervening variables worth investigation in further studies.

\section{References}

1 Sleep-related breathing disorders in adults: recommendations for syndrome definition and measurement techniques in clinical research. The Report of an American Academy of Sleep Medicine Task Force. Sleep 1999;22(5):667-689

2 Tufik S, Santos-Silva R, Taddei JA, Bittencourt LRA. Obstructive sleep apnea syndrome in the Sao Paulo Epidemiologic Sleep Study. Sleep Med 2010;11(5):441-446
3 Young T, Palta M, Dempsey J, Skatrud J, Weber S, Badr S. The occurrence of sleep-disordered breathing among middle-aged adults. N Engl J Med 1993;328(17):1230-1235

4 Noal RB, Menezes AMB, Canani SF, Siqueira FV. Habitual snoring and obstructive sleep apnea in adults: population-based study in Southern Brazil. Rev Saude Publica 2008;42(2):224-233

5 Lipp MEN. Como Enfrentar o Stress. 5th Ed. São Paulo, Brazil: Ícone Editora.; 1998

6 Lipp MEN. O Stress: Conhecer e Enfrentar. 5th Ed. São Paulo, Brazil: Ed. Contexto.; 2003

7 Głebocka A, Kossowska A, Bednarek M. Obstructive sleep apnea and the quality of life. J Physiol Pharmacol 2006;57(Suppl 4):111-117

8 Lipp MEN. Pesquisas Sobre Stress no Brasil: Saúde, Ocupações e Grupos de Risco. Campinas, Brazil: Ed. Papirus.; 2001

9 Grunstein RR, Stewart DA, Lloyd H, Akinci M, Cheng N, Sullivan CE. Acute withdrawal of nasal CPAP in obstructive sleep apnea does not cause a rise in stress hormones. Sleep 1996;19(10):774-782

10 Spiegel K, Leproult R, Van Cauter E. Impact of sleep debt on metabolic and endocrine function. Lancet 1999;354(9188):1435-1439

11 Späth-Schwalbe E, Gofferje M, Kern W, Born J, Fehm HL. Sleep disruption alters nocturnal ACTH and cortisol secretory patterns. Biol Psychiatry 1991;29(6):575-584

12 Buckley TM, Schatzberg AF. On the interactions of the hypothalamic-pituitary-adrenal (HPA) axis and sleep: normal HPA axis activity and circadian rhythm, exemplary sleep disorders. J Clin Endocrinol Metab 2005;90(5):3106-3114

13 Tomfohr LM, Edwards KM, Dimsdale JE. Is obstructive sleep apnea associated with cortisol levels? A systematic review of the research evidence. Sleep Med Rev 2012;16(3):243-249

14 Lipp MEN, Tanganelli MS. Stress e Qualidade de Vida em Magistrados da Justiça do Trabalho: Diferenças entre Homens e Mulheres. Psicol Reflex Crit 2002;15(3):537-548

15 Bittencourt LRA, Silva RS, Santos RF, Pires MLN, Mello MT. Excessive daytime sleepiness. Rev Bras Psiquiatr 2005;27(Suppl 1):16-21

16 de Lima AM, Franco CM, de Castro CM, Bezerra Ade A, Ataíde L Jr, Halpern A. Effects of nasal continuous positive airways pressure treatment on oxidative stress and adiponectin levels in obese patients with obstructive sleep apnea. Respiration 2010;79(5): 370-376

17 Calais SL, Andrade LMB, Lipp MEN. Diferenças de Sexo e Escolaridade na Manifestação de Stress em Adultos Jovens. Psicol Reflex Crit 2003;16(2):257-263

18 Calais SL. Diferenças entre homens e mulheres na vulnerabilidades ao stress. In: M.E.N. Lipp, (Org.). Mecanismos Neuropsicofisiológicos do Stress: Teoria e Aplicações Clínicas. São Paulo, Brazil: Casa do Psicólogo.; 2003:87-89

19 Bardwell WA, Norman D, Ancoli-Israel S, et al. Effects of 2-week nocturnal oxygen supplementation and continuous positive airway pressure treatment on psychological symptoms in patients with obstructive sleep apnea: a randomized placebo-controlled study. Behav Sleep Med 2007;5(1):21-38

20 Derderian SS, Bridenbaugh RH, Rajagopal KR. Neuropsychologic symptoms in obstructive sleep apnea improve after treatment with nasal continuous positive airway pressure. Chest 1988;94(5): 1023-1027

21 Li HY, Huang YS, Chen NH, Fang TJ, Liu CY, Wang PC. Mood improvement after surgery for obstructive sleep apnea. Laryngoscope 2004;114(6):1098-1102

22 Cahali MB, Formigoni GGS, Gebrim EMMS, Miziara ID. Lateral pharyngoplasty versus uvulopalatopharyngoplasty: a clinical, polysomnographic and computed tomography measurement comparison. Sleep 2004;27(5):942-950

23 Cahali MB. Lateral pharyngoplasty: a new treatment for obstructive sleep apnea hypopnea syndrome. Laryngoscope 2003; 113(11):1961-1968 